well corked bottle, for a long time. It is, in fact, a kind of thick varnish. To make the resin.cloth, as I term it, for the sake of distinguishing it from the cere-cloth dressing for wounds, which I described in a paper read at the Leeds meeting of the British Medical Association in 1869 , it is needful to select a very thin, cheap, porous calico, or calico-muslin, known in the trade as "mulls", which costs at wholesale price about four shillings per piece of twenty yards. This, divided into strips, each about nine inches wide and six yards long, is reduced to a convenient form for general use. The calico should be unbleached and free from stiffening, and each of the strips should be carefully folded up, so as just to lie flatly in the press, as I am about to explain.

An ordinary square tincture press may be used to press the cloth, or such a press as is sold for copying letters, to which a tin box has been adapted, so that the plates of the press can work in it; and into this box the folded calico is placed, the solution being poured over each successive layer, so as to wet perfectly every part of it. There should be an aperture at the bottom of the box, with a tap by which the superfluous fluid can be removed, collected, and used a second time. The press being brought into action, the pile of calico should be squeezed as dry as possible, all the fluid drained off, the resin-cloth taken out, laid over a few lines of string in a warm room with a good ventilation; and in an hour or two, when all traces of smell of the methylated spirit have departed, the cloth may be rolled up and kept in tin cases ready for use.

It is difficult for me to state the exact cost of resin-cloth made by this process, for I have not yet bought the materials for its preparation at such prices as could be had if it were to be manufactured in large quantities; but, allowing for some slight reduction, where six or eight twenty-yard pieces of calico are bought at a time, and the solution made by the gallon, I find it comes to a fraction less than threepence per yard of average width of 44 inches. In using it as a dressing for wounds, I deal with it precisely as I would do with Mr. Lister's antiseptic gauze, for which it must be taken as a cheap and ready substitute. I generally apply ten folds of it over the face of a wound, as in an amputation, and perhaps six folds higher up the limb for some distance, and I cover it with the macintosh hat-lining, so as to distribute the serous discharges through the breadth of the resin-cloth thus covered. I have never found it to irritate the skin in any degree beyond what the oiled silk (protective), liberally used, could control ; except once, when, in the hurry of preparing the resin-cloth, I had neglected to dry it thoroughly, and it was applied, still moist with the methylated spirit, the naphtha in it seeming to be the chief cause of the skin-irritation. But if this precaution be observed, I believe this resin-cloth will be found a very useful addendum to our means of treating wounds and abscesses on antiseptic principles.

\section{A CASE OF TUBERCULAR LEPROSY.}

By GEORGE GASKOIN, EsQ., Surgeon to the British Hospital for Diseases of the Skin

J. M., aged 29, native of Herefordshire, a stonemason by trade, eighteen months since migrated to Sussex, where he has not stayed very long in any one place. The last four months he has been in town, much of the time in a general hospital. He is a married man, not of the lowest class or necessitous; his general health is not bad; he is tall, pale, and of phlegmatic complexion, sluggish in manner, with intellect at present rather dull. According to his relation, about nine months since he had very severe shiverings, immediately followed by swelling and inflammation in the right leg and foot, with some attendant fever. After three or four days, the swelling in part subsided, but the same circumstance was many times repeated; whenever there occurred a swelling of the leg, this had been preceded by a shivering. "Very red it was"; at last much thickening remained. Since being in town, the patient has ceased to have these shiverings; when they first came on, there was a fortnight or so of interval. He left off work last Christmas. The appearance of the leg is scarred or scabious, somewhat dark and rough, a case of elephantiasis Arabum, which one might even suppose of older date, and of no insignificant dimensions. Besides this, a red brand is very conspicuous on the left cheek. It crosses from mouth to temple; it is hard and tubercular, all of one piece. It came on when he was in hospital. On the right side of the neck are old scars from glandular ulcerations. These have recently become red and to some extent the seat of tubercular deposit, extending to the cheek and back of the neck. On the right shin, half-way down, there is a considerable projecting tubercle, the size of a small walnut, retaining the colour of the surrounding skin. On the opposite limb are smaller but corresponding tubercles. The four outer tces of the affected foot display on their dorsal surface a projecting tubercular mass distinct from the general swelling. On this part there was previously a scar or trace from an injury received when a boy. Also in the affected cheek there is seen a small scar, with the history of a blow of more recent date. The tendency of the disease, as it would seem, is to fall on parts where vitality is impaired or the circulation low. The roice is not affected.

This case serves to confute the idea that elephantiasis Arabum is a local disease. The present condition of the patient comes very near to elephantiasis Gracorum, if not already merged into this. It has not seemed sufficient, however, for modern pathologists to distinguish the two diseases; the difference has heen strained to the uttermost, but, being a mere idol of the theatre, the conclusion can have no permanency.

\section{THE CONNECTION OF DIPHTHERIA WITH LOCAL UNSANITARY CONDITIONS.*}

BY WV. N. THURSFIELD, M.D.,

Medical Officer of Health for the Shropshire Combined Sanitary District.

MY object in this paper is to endeavour to elicit an opinion from you as to the exact connection between diphtheria and local unsanitary conditions, as this is a point about which there is much uncertainty, and on which members of a society constituted as yours is to a large extent are particularly well qualified to speak with authority. There are many points connected with the etiology of disease, especially as to the origin of certain diseases di novo, about which the observations of practitioners in country districts are of much more value than those of their brethren in large towns. They have a more intimate acquaintance with the habits, movements, and surroundings of their patients, and often they have a complete knowledge of all probable sources of infection in a district, and can thus eliminate various sources of error in a way not possible under more crowded conditions of life.

As the term diphtheria is occasionally somewhat loosely applied, I will define it to mean a systemic contagious disease, characterised by a tendency to membranous exudation, chiefly affecting the pharynx, and having ihese peculiarities, that, during its course, albumen is frequently present in the urine, and that the disease is liable to be followed by obscure local nervous affections. Another peculiarity of the disease is the remarkable and now well proved influence of hereditary predisposition ; in determining personal susceptibility, this, in conjunction with the tenacity with which the contagion element in this disease is liable to remain in a room, unless great precautions be taken, may explain some of the cases where diphtheria has been noticed as recurring several times in the same house.

The medical practitioners with whom I come into contact in this country almost invariably connect diphtheria with local unsanitary conditions, and many of them are of opinion that such conditions not unfrequently originate the disease. On looking through the systematic works on medicine, both English and foreign, I have been struck by the almost complete absence of any reference to a connection between this disease and local influences. In the collection of monographs on the subject published by the New Sydenham Society, one author only, M. Empis, refers to it, and only so far as this, that "the disease is most obstinate, and relapses of the local symptoms most common, in weakly children surrounded by sanitary deficiencies." M. Trousseau states that "he has seen the disease raging on salubrious heights, whilst villages situated in marshy districts have escaped, and rice versa." In this country it has also been observed in several epidemics that the disease has prevailed with great fatality on elevated and exposed tracts of country; those of us, however, who are in the habit of making sanitary investigations in country districts know that many localities with the greatest natural advantages of site and air often exhibit, both inside and outside the houses, the worst forms of sanitary neglect, with which the pure winds in vain battle. The elaborate series of investigations, extending to upwards of seventy localities, made for the Medical Department of the Privy Council by Drs. Sanderson and Greenhow on the subject of this disease, and published in the second report (1859) of the medical officer to the Privy Council, do not seem to justify any definite conclusion on this particular point; but, in reporting a subse. quent investigation, published in the eighth report $(1865)$ of the medical officer to the Privy Council, Dr. Sanderson states, in reference to an outbreak of diphtheria, that "it is not possible to avoid the conclusion that it was due to local causes, and that it would have been prevented if the nuisance had been effectually abated."

* Abstract of a paper read before the Shropslire Scientific Branch of the British Medical Association. 